\title{
Sentimentos Predominantes Após o Término de um Relacionamento Amoroso
}

Predominant feelings after the end of a love relationship

Mariana Valença

Marcondes, Michele

Trierweiler \& Roberto

Moraes Cruz

Universidade Federal

de Santa Catarina

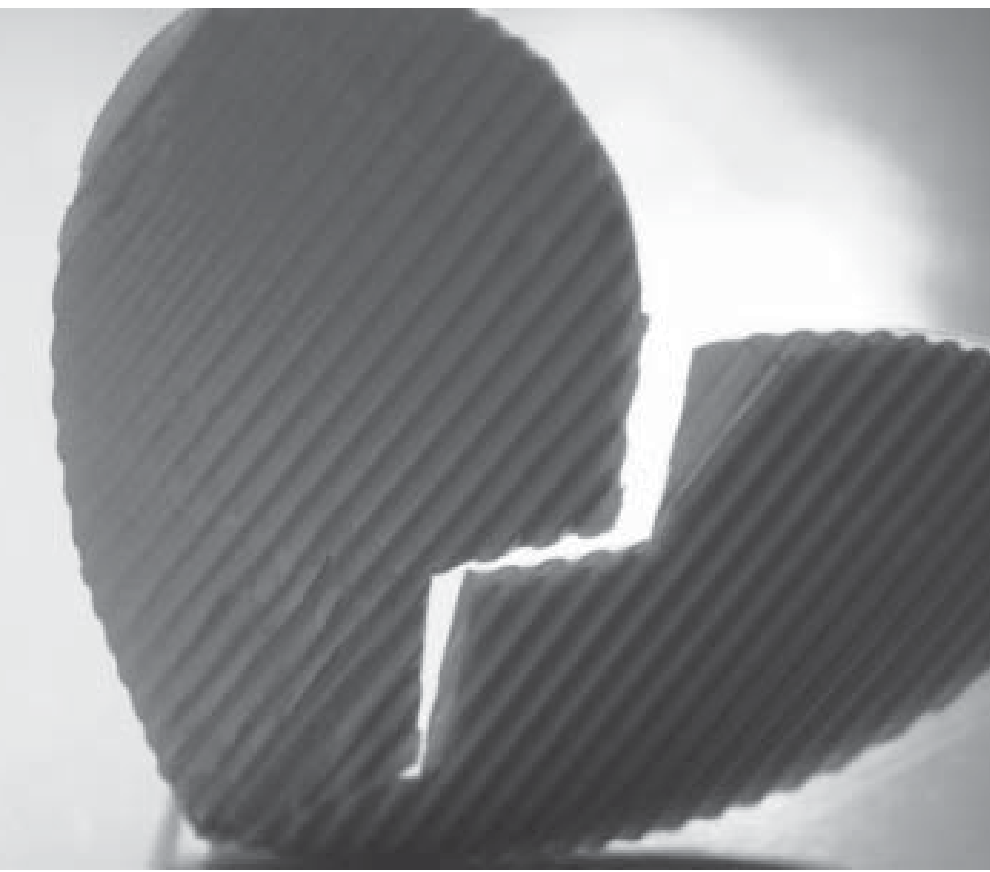




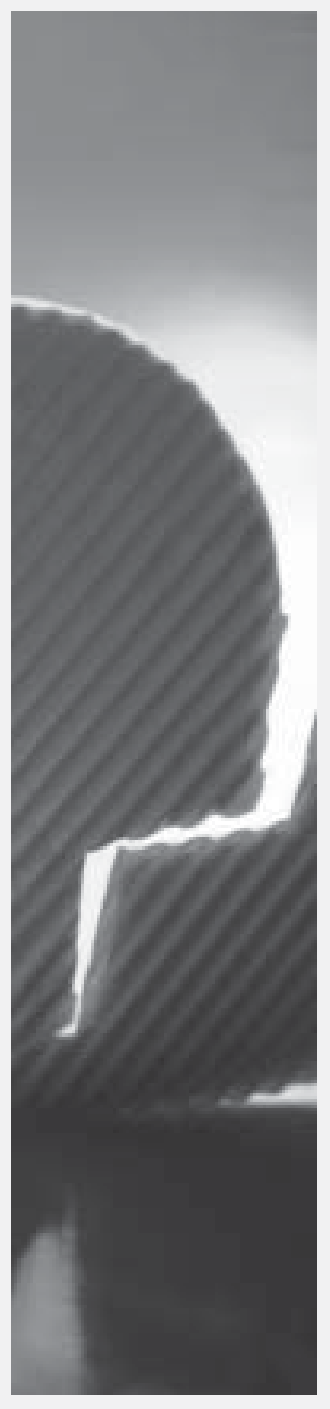

Resumo: O objetivo deste trabalho foi investigar os sentimentos que predominam após o término de relacionamentos amorosos e as diferenças de intensidade quanto ao gênero, iniciativa de término e duração do relacionamento. Participaram da pesquisa 68 sujeitos, com idades entre 17 e 44 anos, sendo 37 homens e 31 mulheres. Foi construída uma escala de atitudes baseada no modelo Likert, contendo 37 afirmativas referentes a sentimentos negativos e positivos, e estabeleceu-se uma equivalência entre as expressões da escala e a atribuição de valor. Houve diferença na média das pontuações dos sentimentos negativos: no tempo de duração da relação, no tempo de término do relacionamento e na relação afetiva após término da relação. De um modo geral, a separação provoca abalo emotivo tanto em homens como em mulheres, nas diferentes situações.

Palavras-chave: relacionamento amoroso, medidas psicológicas, escala de atitude.

Abstract: The main purpose of this study is to investigate the predominant feelings after love relationship endings and its different intensity relating with gender, initiative of ending and length of relationship. Sixty eight people participated in this study, thirty seven were man and 31 women, age range 17 to 44 . An attitude scale based on the Likert model was built to evaluate thirty seven relevant characteristics related to positive and negative feelings. Results were based on equivalence between attributed value and scale expression. Results showed that there were differences on averages related to negative feelings associated with relationship duration, length of ending and relationship after the ending. Generally relationship endings cause emotional commotion both for men and women in several situations.

Key words: love relationship, assessment, attitude scale.

A presente pesquisa teve como objetivo investigar os sentimentos que predominam no término de relacionamentos amorosos, testando hipóteses levantadas a partir da literatura, já existentes sobre o assunto, de que sentimentos negativos, que são os sentimentos associados à infelicidade e ao mal-estar, são os mais freqüentes nesses casos. Buscou-se, ainda, averiguar algumas possíveis diferenças na intensidade dos sentimentos nos homens e nas mulheres. É possível afirmar que existem algumas características que são constantes e gerais dos estados emotivos e psíquicos próprios dos momentos de separação, particularmente dolorosos e difíceis de superar, mesmo cada indivíduo sendo único e cada experiência de vida nunca se repetir em sua especificidade. A dor da separação é, com freqüência, fisicamente sentida. São comuns as dores no peito e a sensação de peso, sufocamento e falta de ar (Maldonado, 1995). Além disso, a incapacidade de trabalhar efetivamente, má saúde, mudanças no peso, disfunção sexual, insônia e outros transtornos do sono também são freqüentes (Carter \& Mcgoldrick, 1995). Cada separação tem uma história e, quase sempre, provoca um abalo emotivo que,
Ah, se já perdemos a noção da hora se juntos já jogamos tudo fora me conta agora como hei de partir. Se, ao te conhecer, dei pra sonhar, fiz tantos desvarios rompi com o mundo, queimei meus navios me diz pra onde que ainda posso ir. "Eu Te Amo" - Tom Jobim e Chico Buarque. 
Caruso afirma que estudar a separação amorosa significa estudar a presença da morte na vida. segundo Giusti (1987), na escala das causas de estresse, vem imediatamente após a morte de um parente ou o choque de ser preso, e que pode ser considerado equivalente ao trauma causado pela perda da única fonte de subsistência. Quando o relacionamento se rompe, o trabalho necessário para recuperar o equilíbrio emocional e existencial requer um dispêndio de energia psíquica, e esse dispêndio, freqüentemente, provoca deterioração física e nervosa, tal como ocorre durante um luto grave. Caruso (1981) afirma que estudar a separação amorosa significa estudar a presença da morte na vida. Referindo-se ao ditado francês partir c'est mourrir un peu (partir é morrer um pouco), Caruso (1981, p.12) afirma que, na separação, há uma sentença de morte recíproca: "o outro morre em vida dentro de mim e eu também morro na consciência do outro".

Segundo Freud (1974), o luto profundo, como reação à perda de alguém que se ama, pode ser resumido como um estado de espírito penoso, na cessação de interesse pelo mundo externo, na perda da capacidade de adotar um novo objeto de amor (o que significa substituí-lo) e no afastamento de toda e qualquer atividade que não esteja ligada a pensamentos sobre ele. O indivíduo em luto geralmente experimenta um desejo de reparar a perda e destruir o objeto que foi internalizado como "bom" (Baker, 2001). É impossível prever quanto tempo durará o "período de luto", assim como é difícil determinar o momento em que ele começa efetivamente (Giusti, 1987). Segundo FéresCarneiro (1998), o tempo de elaboração do luto pela separação pode ser maior do que aquele do luto por morte.

Na medida em que a separação constitui a tão desejada solução para um problema que não poderia ser resolvido de outra forma, deveria, então, ser vivida como uma sensação de alívio, mas a mobilização emocional pósseparação, tal como percebida por Maldonado
(1995), é intensa, pois a pessoa está diante do medo, da incerteza, da insegurança, que caracterizam a mudança de aspectos importantes de si mesmo. São comuns as atitudes irracionais, ilógicas e impulsivas.

A separação não é só o fim de uma união material, mas também a quebra de vínculos, de laços emotivos, sexuais e afetivos, criados, segundo Giusti (1987), tanto pelo amor como pelo ódio, pelas brigas e pelas reconciliações. Dependendo de quem é o responsável pelo término da relação, diferentes tipos de dor são sentidas. Embora seja considerado ruim para ambos, costuma sofrer mais aquele que é percebido como deixado. Não porque a separação não doa na pessoa que terminou, mas, segundo Colasanti (1986), porque este, para aliviar sua dor, tem o estímulo do impulso que o levou a agir e o sentido de renovação. Para quem quer separar-se, o que predomina, inicialmente, é o alívio, às vezes a euforia, por se ver livre do peso e da tensão da situação infeliz. A sensação de alívio amortece o impacto. Há a novidade, as mudanças, a passagem de um passado conhecido para um futuro sem previsões. Depois, costumam vir culpa e tristeza. Surgem aí, com toda força, os bons momentos, sonhos desfeitos, a tristeza pelo que poderia ter sido, mas não foi, pelo que não foi possível manter.

Os sentimentos de ódio e frieza, nessas horas, surgem para suavizar ou neutralizar os sentimentos de pesar e de culpa, que talvez doam muito mais. Pensar com raiva só nas coisas ruins anestesia a dor de lamentar o que não deu certo. Em meio ao ódio, ao ressentimento e à dor, vem a tendência a denegrir, difamar e rebaixar o ex-parceiro para convencer-se de que não perdeu grande coisa. Se, aos olhos da pessoa, o outro fica desprezível, será mais fácil acabar. Os defeitos se ressaltam, as qualidades passam para segundo plano no esforço de sentir menos as perdas ou de não se arrepender da decisão de separar-se (Maldonado, 1995). Quanto mais 
longa e íntima for a união, provavelmente mais desolador será o momento da separação, mesmo se a intimidade era produto de sofrimentos, incompreensões e ofensas (Giusti, 1987).

Diante da percepção de que a decisão do outro é irreversível, costuma vir a depressão, quase sempre acompanhada pelos sentimentos de autodepreciação, pena de si mesmo, baixa auto-estima. As etapas se mesclam, principalmente a depressão com autodesvalorização e a raiva com o ataque ao parceiro, a vingança e a hostilidade (Maldonado, 1995; Mearns, 1991). A depreciação da pessoa amada, segundo Klein e Rivière (1975), pode ser um mecanismo útil de vasta aplicação que nos permite suportar decepções sem nos tornarmos selvagens. Um certo grau de depreciação de qualquer pessoa ou coisa querida a que se renunciou é provavelmente inevitável, mesmo se configurada em pouco mais que a descoberta do fato de que a pessoa, ou coisa desejada, fora exageradamente idealizada.

É difícil deixar de pensar a respeito da vida e dos atuais sentimentos do nosso antigo companheiro: se ele sente nossa falta, se precisa de nós ou se está reconstruindo sua própria vida. As possíveis novas relações do parceiro podem dar início ao ciúme, inclusive em quem nunca o sentiu. "É possível que um indivíduo deseje estar - ou mesmo, no nível da fantasia, sinta-se - comprometido com uma pessoa amada sem que a recíproca seja verdadeira, e, nesse caso, a interferência de um rival pode gerar o ciúme, apresentando as mesmas características de uma situação triangular real" (Ramos, 2000, p. 32).

O ciúme e o sentimento de posse emergem, especialmente, quando se perdem todos os direitos: se antes tínhamos "o direito de amor exclusivo" sobre uma pessoa, quando ele cessa de existir, surge uma profunda sensação de frustração e de impotência. Às vezes ocorre que, depois da separação, ao mesmo tempo em que se aguça o desejo de possuir e de controlar o outro, acaba-se perdendo toda a motivação para viver e experimenta-se a penosa sensação de estar à deriva (Giusti, 1987). Para Wilson (2000), o término de um romance, mesmo o primeiro, pode disparar uma depressão vitalícia, principalmente nas pessoas que têm uma vulnerabilidade predeterminada a vicissitudes românticas e a deprimir-se durante tais períodos difíceis.

Há pessoas que se protegem do impacto emocional da separação fazendo uma defesa de "anestesia afetiva total" (Maldonado, 1995, p.122): "Eu estou tão estranha, não consigo sentir nem alegria nem tristeza". Há quem se isole, preferindo ficar sozinho ou em contato com pouca gente para ter a sensação de paz e de alívio. Vilhena (1991), ao referir-se à separação, enfatiza a questão da "capacidade de ficar só" dos sujeitos e distingue diferentes formas de solidão.

A solidão pode representar uma possibilidade de ficar consigo mesmo ou uma incapacidade de tolerar a indiferença do outro, manifestando-se tanto no isolamento voluntário como na busca compulsiva de companhia. Pouco a pouco, porém, as emoções que nos mantêm impossibilitados de reagir vão sendo reelaboradas e vividas de maneira mais direta e menos dilacerante. "Somos indivíduos reprimidos pelo proibido e pelo impossível, que procuram adaptar-se a seus relacionamentos extremamente imperfeitos. Vivemos de perder e abandonar, e de desistir. E, mais cedo ou mais tarde, com maior ou menor sofrimento, todos nós compreendemos que a perda é, sem dúvida, uma condição permanente da vida humana" (Viorst, 1988, p. 243).
A solidão pode representar uma possibilidade de ficar consigo mesmo ou uma incapacidade de tolerar a indiferença do outro, manifestando-se tanto no isolamento voluntário como na busca compulsiva de companhia. 


\section{Método}

\section{Participantes}

Foram pesquisadas 68 pessoas, sendo 31 mulheres e 37 homens, com idades entre 17 e 44 anos, sendo que a média de idade era de 21 anos, durante os meses de junho e setembro de 2002. Como pré-requisito para participar da pesquisa, era necessário que o sujeito já tivesse vivenciado um término de relacionamento amoroso.

\section{Material e procedimento}

Foi construída uma escala de atitudes intitulada Sentimentos Predominantes Após o Término de Relações Amorosas (Anexo), contendo 7 questões para a caracterização dos participantes e do término do relacionamento amoroso e 37 afirmativas, sendo 8 relacionadas a atitudes positivas e as 29 restantes relacionadas a atitudes negativas. Conforme Cruz (2002) e Medeiros (1999), a medida atitudinal tem por finalidade revelar as disposições gerais relativamente estáveis e típicas para perceber fatos, pessoas ou objetos e a eles reagir, em postura que revela crenças e valores.

Consideraram-se como positivos os sentimentos ligados ao bem-estar e à melhoria no estado geral da pessoa, e, como negativos, os sentimentos ligados à infelicidade e ao malestar. As afirmativas foram respondidas objetivamente, assinalando-se uma das cinco respostas referentes ao grau de intensidade nunca, pouco, moderadamente, freqüentemente, extremamente - da escala de atitudes. Para cada proposição da escala, foi atribuído um valor entre 0 e 4, conforme a intensidade do sentimento vivenciado pela pessoa.

Primeiramente, foi realizado um pré-teste, de tipo Likert (Baquero, 1968), com 40 afirmativas construídas a partir da avaliação dos atributos do fenômeno investigado. Essa versão preliminar foi submetida a 10 sujeitos, e, posteriormente, sofreu alterações que visavam a uma melhor mensuração dos resultados e evitassem ambigüidade de interpretação das questões.

A escala foi aplicada entre estudantes universitários e profissionais da cidade de Florianópolis, tomando-se o cuidado para que as pessoas respondessem individualmente e não fossem identificadas. Todos concordaram em participar de forma livre e consentida.

\section{Resultados e discussão}

A partir das medidas das questões da escala, constatou-se que os participantes que atingiram, nas questões referentes a atitudes positivas, uma pontuação maior que a metade de pontos possíveis (acima de 16 dos 32 pontos), tenderam a apresentar pontuações mais baixas nas questões sobre atitudes negativas, isso quando comparados às pessoas que obtiveram uma pontuação igual ou menor que 16 pontos nas questões de atitudes positivas, que, por sua vez, tenderam a apresentar pontuações mais altas nas questões de atitudes negativas.

Com base nesses resultados, principalmente nos das questões sobre atitudes positivas, e com o intuito de facilitar a visualização dos mesmos, os participantes foram distribuídos em dois grupos: o Grupo A, que são as pessoas que apresentaram uma tendência de sentimentos positivos referentes ao final de um relacionamento (acima de 16 pontos nas questões de atitudes positivas), e o Grupo B, formado pelas pessoas com uma tendência a sentimentos negativos diante de uma mesma situação (16 pontos ou menos). Logo abaixo, na Figura 1, observa-se a porcentagem de pessoas em cada um dos grupos, distribuído conforme o sexo. 

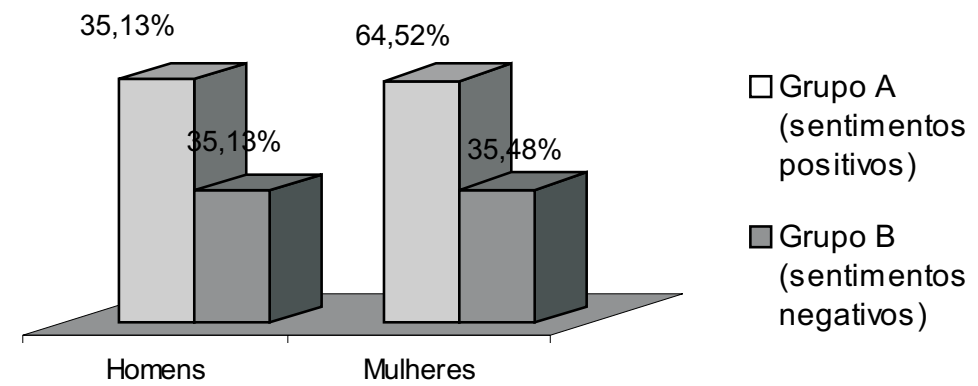

Figura 1 - Distribuição percentual das medidas de sentimentos positivos e negativos conforme o sexo.

Os escores obtidos por homens e mulheres foram semelhantes nos dois grupos. Dos 37 homens que participaram da pesquisa, 64,87\% estão incluídos no Grupo A, e 35,13\%, no Grupo B, e, das 31 mulheres, 64,52\% e 35,48\% respectivamente. As questões de atitudes positivas (vide anexo1) que receberam maior pontuação estão na tabela abaixo:

Tabela 1-Atitudes positivas mais pontuadas, conforme o sexo.

\begin{tabular}{l|l}
\multicolumn{1}{c|}{ Homens } & \multicolumn{1}{c}{ Mulheres } \\
\hline "Tive sensação de liberdade" & "Tive sensação de liberdade" \\
\hline "Tive pensamentos positivos" & "Senti alívio" \\
\hline "Minha auto-estima era boa" & "Estava satisfeita com minha nova vida" \\
\hline "Consegui distrair-me com outras coisas" & "Senti motivação para buscar novas possibilidades \\
& na vida"
\end{tabular}

Nas questões referentes às atitudes negativas, o menor valor alcançado foi 04, e o maior foi 76 da pontuação máxima possível (116 pontos). Verificou-se, nos valores de 4 a 29 pontos, uma tendência à positividade com relação ao término, relacionando-se, assim, com o Grupo A. Dentro desse grupo, foram definidos dois intervalos para melhor visualização da intensidade dos sentimentos negativos e a sua freqüência em cada sexo. Assim, constatou-se que, até 14 pontos, a pontuação foi mais freqüente nos homens (35,13\%) que nas mulheres (12,9\%); já do intervalo 15 a 29 pontos, essa freqüência foi mais equilibrada: 35,13\% dos homens e 32,26\% das mulheres.

Da pontuação de 30 até 76, foi constatada uma decrescente tendência à positividade dos sentimentos, podendo ser incluídos no Grupo B. Dentro desse grupo, foram definidos três intervalos. De 30 a 44 pontos, considerado um nível moderado de negatividade por tender a apresentar pontuações relativamente altas nas questões de atitudes positivas, a diferença entre homens e mulheres é: 10,81\% dos homens e 19,35\% das mulheres. De 45 a 68 pontos, percebido como um nível alto, 16,22\% dos homens e 29,04\% das mulheres alcançaram esse valor. O valor acima de 68 pontos é representado por 2,71\% dos homens e 6,45\% das mulheres, que é o nível mais altos de sentimentos negativos quanto ao fim de uma relação. Na Figura 2, pode-se verificar a freqüência das atitudes negativas nos homens e mulheres. 


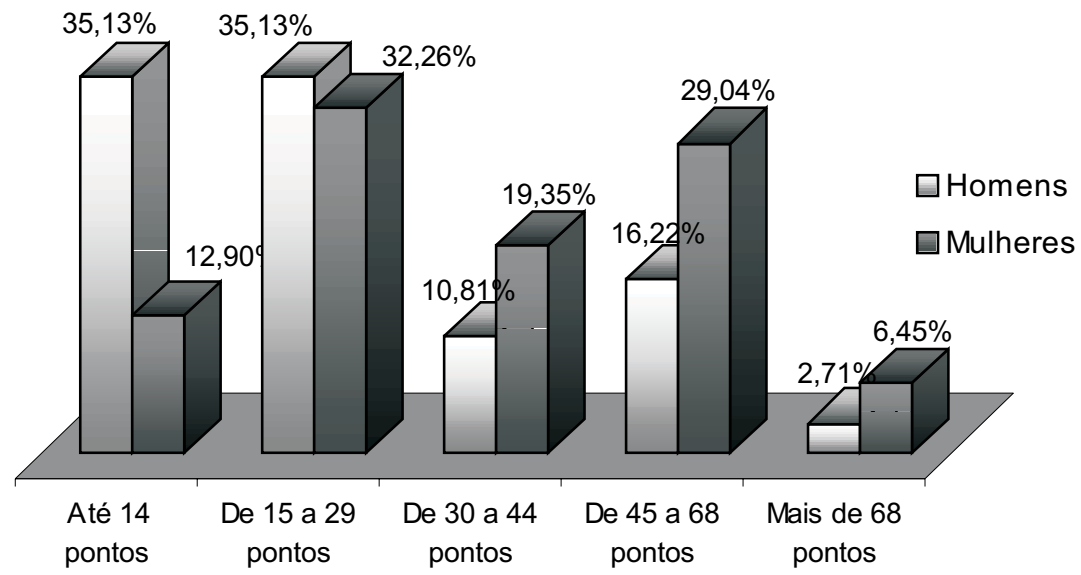

Figura 2 - Distribuição das atitudes negativas, segundo o sexo

Constatou-se, com esses resultados, que ambos os sexos apresentaram resultados semelhantes relacionados aos sentimentos positivos. No entanto, houve uma predominância das atitudes negativas nas mulheres, sendo que elas atingiram níveis maiores quando comparadas aos homens, o que pode sugerir que as mulheres tendem a ter a percepção de um maior sofrimento diante dessa situação.

Conforme Galisson (2001), em seu artigo Marital Blues Bring IIls, as mulheres são mais sensíveis cognitiva e emocionalmente às angústias dos relacionamentos amorosos que os homens. Mearns (1991), em Coping With a Breakup: Negative Mood Regulation Expectancies and Depression Following the End of a Romantic Relationship, afirma que homens e mulheres diferem na depressão provocada após o término: as mulheres relatam uma depressão mais severa.

A figura que segue (Figura 3) mostra a descrição das médias dos sentimentos negativos conforme a pessoa que tomou a iniciativa do término da relação.

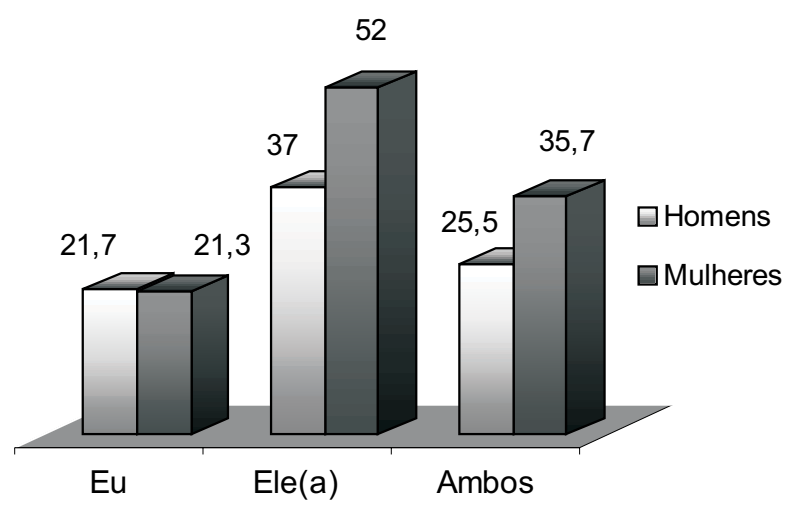

Figura 3 - Distribuição percentual das médias dos sentimentos negativos. conforme a pessoa que tomou a iniciativa do término da relação amorosa. 
Assim, entre os sujeitos que terminaram a relação, os valores foram 21,7 para os homens e 21 para as mulheres, não ocorrendo diferença entre os sexos; foi essa a categoria que atingiu menor valor de atitudes negativas. Quando ambos terminam a relação, as mulheres $(35,7)$ apresentaram maiores pontuações nas atitudes negativas do que os homens $(25,5)$. Quando foi o parceiro que tomou a iniciativa do término, os níveis foram os mais altos das três categorias, atingindo 37 pontos nos homens e 52 pontos nas mulheres. As mulheres, também nessa situação, apresentaram valores mais elevados para atitudes negativas que os homens. Podemos relacionar esses valores com a teoria de Maldonado (1995, p. 97), segundo a qual "quem deixa e quem é deixado sente diferentes tipos de dor". De acordo com essa pesquisa, uma maior negatividade ou "dor" ocorre entre as pessoas que foram percebidas como deixadas.

Na pesquisa de Mearns (1991), as pessoas que terminaram o relacionamento recentemente (primeiras semanas) apresentaram níveis mais altos de depressão. Dessa forma, esperava-se, na nossa pesquisa, que o período logo após o término fosse mais crítico quanto aos sentimentos negativos. No entanto, o que ocorreu na população pesquisada (Figura 4) foi que os sujeitos que terminaram a relação há um período de 4 meses a 1 ano, nas mulheres $(37,71)$, e no período de mais de 1 ano, nos homens (26,57), apresentaram valores mais elevados que o período mais recente (de até 3 meses) após o término. Esses resultados podem ser mais bem compreendidos a partir da afirmação de Giusti (1987), de que é difícil determinar o momento em que o período de luto e de sofrimento começa efetivamente e prever quanto tempo ele vai durar. Provavelmente, nos primeiros meses após o término, a pessoa ainda não se deu conta da sua real situação. De acordo com Maldonado (1995), logo após o término, pode haver uma sensação de liberdade, de alívio, de euforia. Isso poderia explicar os maiores níveis de sentimentos negativos após 4 meses do fim da relação.

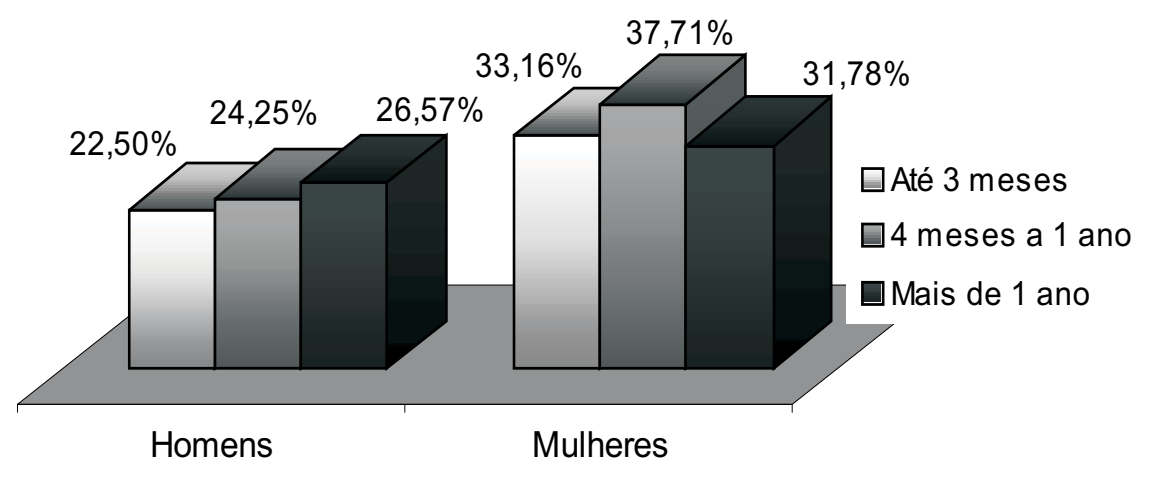

Figura 4 - Distribuição percentual dos sentimentos negativos, de acordo com o tempo do término de uma relação amorosa, em homens e mulheres.

Houve, quanto à duração da relação, uma predominância de atitudes negativas nos homens quando o relacionamento durou mais de 1 ano (Figura 5). Nas mulheres, houve maior predominância de atitudes negativas nos relacionamentos que duraram de 7 meses a 1 ano, ao contrário dos homens, que obtiveram o menor valor nessa categoria. Os valores são semelhantes nos períodos 
até 6 meses e mais de 1 ano. De acordo com Giusti (1987), os relacionamentos mais duradouros seriam os que mais causariam sofrimento após o término, mas, nessa pesquisa, observou-se que mesmo os relacionamentos mais curtos também causam sofrimento. E a intensidade deste pode ser até maior nos relacionamentos de curto período. Nos homens, por exemplo, os sentimentos negativos foram maiores no período de até 6 meses em relação ao de 7 meses a 1 ano.

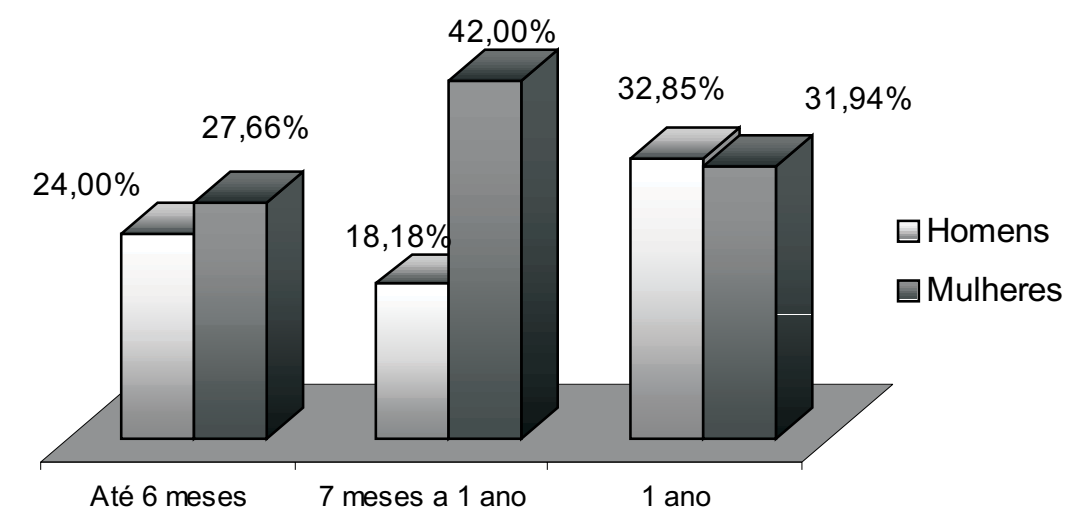

Figura 5 - Distribuição percentual dos sentimentos negativos de acordo com o tempo de duração do relacionamento segundo o sexo.

\section{Conclusão}

Com esta pesquisa, procurou-se abranger, da melhor forma possível, a intensidade dos sentimentos predominantes no fim de uma relação amorosa. Por se tratar de uma amostra pequena (68 pessoas), cabe pontuar que os resultados obtidos têm uma função mais ilustrativa do que conclusiva. Dessa forma, segundo os resultados obtidos com a pesquisa, o sofrimento causado pelo término de um relacionamento amoroso independe do tempo de duração do mesmo. Além disso, há uma predominância de atitudes negativas tanto para homens como para mulheres, embora em intensidades diferentes. As mulheres atingiram níveis maiores de atitudes negativas quando comparadas aos homens, mas, quando analisadas as atitudes positivas nas mesmas situações, os níveis foram semelhantes para ambos.

As pessoas que apresentaram pontuações altas nas questões referentes às atitudes positivas tenderam a apresentar também pontuações baixas nas questões referentes às atitudes negativas e, inversamente, as pessoas com baixas pontuações nas questões de atitudes positivas apresentaram altas pontuações nas questões de atitudes negativas. Há, possivelmente, uma relação entre a presença de um tipo de atitude e a ausência de outro.

Com relação à diferença na intensidade de sofrimento entre homens e mulheres, é interessante considerar o contexto sociocultural em que essas pessoas estão inseridas, já que este pode estar interferindo nas respostas dos sujeitos. No caso dos homens, por exemplo, ainda há uma grande 
cobrança desse contexto, que alimenta a omissão dos sentimentos vinculados aos relacionamentos amorosos.

Dessa forma, é de grande importância que fenômenos relacionados ao amor, à atração e à paixão deixem de pertencer apenas ao domínio dos poetas, compositores e filósofos e passem a ser considerados temas científicos.
Diante de tantos problemas de relacionamento entre os indivíduos, é necessário criar instrumentos de pesquisa que possam auxiliar e analisar de forma científica temas que antes eram considerados obscuros, tornando-os passíveis de medição e fazendo com que eles sirvam como instrumentos auxiliares em programas de intervenção para tais problemas. 


\section{Questionário}

Sentimentos predominantes após o termino de relações amorosas

Este questionário faz parte de uma pesquisa sobre sentimentos que ocorrem em pessoas após o término de um relacionamento amoroso. Por favor, responda as seguintes questões baseando-se em algum relacionamento amoroso seu que já tenha terminado.

Sexo ( )Masculino ( )Feminino

Idade:

Tempo de relacionamento:

Há quanto tempo terminou:

O relacionamento terminou com briga? ( )Sim ( )Não

Quem terminou?( )Eu ( )Ele(a) ( )Ambos

Continuei amando ( )Não ( )Pouco ( )Sim

As questões seguintes referem-se ao período logo após o término do relacionamento.

1. Senti desprezo pela pessoa.
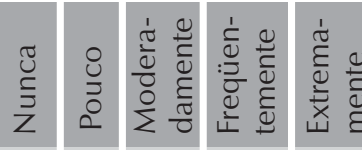

2. Senti-me feliz.

3. Tive medo da solidão.

4. Estava incerto sobre o que fiz.

5. Sentia-me rejeitado.

6. Irritava-me com facilidade.

7. Estava triste e magoado.

8. Sentia-me culpado.

9. Estava desiludido(a).

10. Fiquei traumatizado(a).

11. Arrependi-me do que fiz.

12. Preocupei-me com o que iria acontecer.

13. Fiquei desesperado(a).

14. Isolei-me das outras pessoas.

15. Senti mais ciúmes do que normalmente sentia.

16. Pensei estar derrotado(a).

17. Pensava que era uma grande perda.

18. Fiquei frustrado(a).

19. Tive sensação de liberdade.

20. Sentia-me humilhado(a).

21. Sentia-me fracassado(a).

22. Estava satisfeito com minha nova vida.

23. Sentia-me desvalorizado(a).

24. Evitei envolver-me com outras pessoas.

25. Senti alívio.

26. Tive sentimento de raiva da pessoa.

27. Decepcionei-me com o término.

28. Estava deprimido(a).

29. Senti motivação para buscar novas possibilidades na vida.

30. Chorava com facilidade.

31. Minha auto-estima era boa.

32. Tive pensamentos positivos.

33. Perdi o interesse por minhas atividades.

34. Acreditei não ser interessante para outras pessoas.

35. Senti mal-estar ou dores físicas.

36. Consegui distrair-me com outras coisas.

37. Sentia-me perdido na vida. 


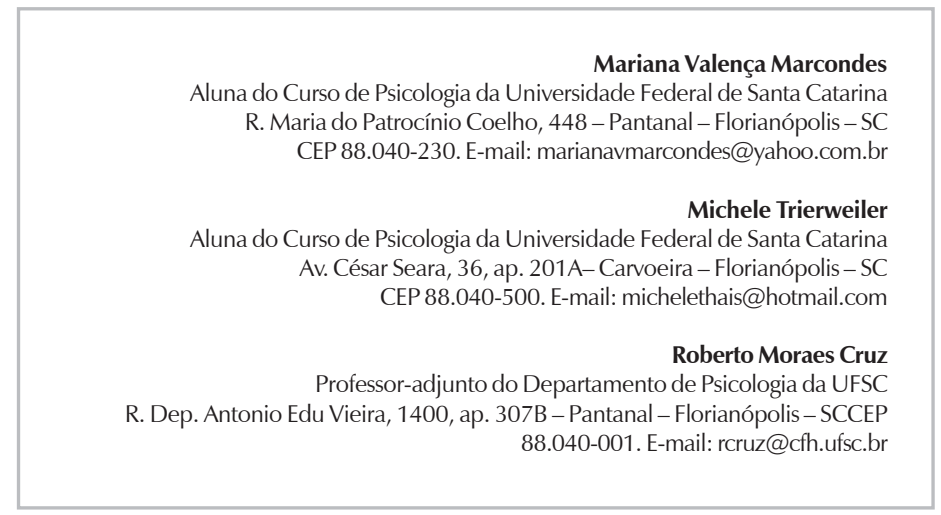

Recebido 05/06/03 Reformulado 30/09/05 Aprovado 14/03/06

BAQUERO, G. Testes Psicométricos e Projetivos: Esquemas para a Construção, Análise e Avaliação. São Paulo: Edições Loyola, 1968. CARUSO, I. A Separação dos Amantes: uma Fenomenologia da Morte. São Paulo: Cortez, 1981.

CATER, B., McGOLDRICK, M. As Mudanças no Ciclo Familiar: uma Estrutura para a Terapia Familiar. Porto Alegre: Artes Médicas, 1995.

COLASANTI, M. E por Falar em Amor. Rio de Janeiro: Rocco, 1986.

CRUZ, R. M. O Processo de Conhecer em Avaliação Psicológica. In Cruz, R. M., Alchieri, J. M. \& Sardá, J. J. Avaliação e Medidas Psicológicas - Produção do Conhecimento e da Intervenção Profissional. São Paulo: Casa do Psicólogo, 2002, pp. 15-24.

FÉRES-CARNEIRO,T. Casamento Contemporâneo: o Difícil Convívio da Individualidade com a Conjugalidade. Psicologia Reflexão e Crítica, 11, no 2. Porto Alegre, 1998, pp. 379-394.

FREUD, S. Luto e Melancolia. Edição Standard Brasileira das Obras Psicológicas Completas de Sigmund Freud, vol. XIV. Rio de Janeiro: Imago, 1974, pp.269-292.

GALISSON, K. Marital Blues Bring Ills. Psychology Today, 34, no 1, 18 Washington, 2001.

GIUSTI, E. A Arte de Separar-se. Rio de Janeiro: Nova Fronteira, 1987.
KLEIN, M. \& J. RIVIÈRE. Amor, Ódio e Reparação. São Paulo: Imago Editora/EDUSP, 1975.

MALDONADO, M. T. Casamento: Término e Reconstrução. São Paulo: Saraiva, 1995.

MEARNS, J. Negative Mood Regulation Expectancies and Depression Following the End of a Romantic Relationship. Journal of Personality and Social Psychology, 60, no 2. New York, 1991, pp.327-334.

MEDEIROS, E. B. Medidas Psico e Lógicas: Introdução à Psicometria. Rio de Janeiro: Ediouro, 1999.

RAMOS, A. L. M. Ciúme Romântico: Teoria e Medida Psicológicas. São Paulo: Stiliano, 2000.

VILHENA, J. Escutando a Família: uma Abordagem Psicanalítica. Rio de Janeiro: Relume-Dumará, 1991.

VIORST, J. Perdas Necessárias. São Paulo: Melhoramentos, 1988.

WILSON, A. Just a Little Crush? Psychology Today, 33, no 16, mai/ jun., Washington, 2000.
Referências 